\title{
$\alpha 7$ nicotinic acetylcholine receptor agonist inhibits the damage of rat hippocampal neurons by TLR4/Myd88/NF-кB signaling pathway during cardiopulmonary bypass
}

\author{
KEYAN CHEN $^{1}$, YINGJIE SUN ${ }^{2}$, YUGANG DIAO $^{2}$, LIU JI $^{2}$, DANDAN SONG $^{2}$ and TIEZHENG ZHANG ${ }^{2}$ \\ ${ }^{1}$ Department of Laboratory Animal Science, China Medical University, Shenyang, Liaoning 110122; \\ ${ }^{2}$ Department of Anesthesiology, General Hospital of Shenyang Military Area Command, Shenyang 110016, P.R. China
}

Received March 1, 2017; Accepted July 27, 2017

DOI: $10.3892 / \mathrm{mmr} .2017 .7166$

\begin{abstract}
The present study aimed to investigate the effect of $\alpha 7$ nicotinic acetylcholine receptor ( $\alpha 7 \mathrm{nAChR})$ agonist on the damage of hippocampal neurons and the expression of toll like receptor 4 (TLR4)/myeloid differentiation primary response 88 (Myd88)/nuclear factor (NF)-кB signal pathway-associated factors in cardiopulmonary bypass (CPB). Sprague Dawley rats were randomly divided into five groups: Sham operation (Sham); CPB; CPB + $\alpha 7 n$ AChR agonist PHA568487 (PHA); $\mathrm{CPB}+\alpha 7 n \mathrm{AChR}$ inhibitor MLA (MLA); and CPB + PHA568487 + TLR4 antagonist (CPT). Blood and brain tissue samples were harvested at $12 \mathrm{~h}$ following the withdrawal of CPB. Levels of serum inflammatory factors [interleukin (IL)-1 $\beta$, IL- 6 and tumor necrosis factor (TNF)- $\alpha$ ] and brain injury markers [S-100 $\beta$ and neuron-specific enolase (NSE)] were measured using ELISA. In addition, pathological histology and apoptosis changes were observed using hematoxylin and eosin staining, and Tunnel assays. Quantitative polymerase chain reaction and western blot assays were used to determine the expression of TLR4, Myd88 and NF- $\mathrm{KB}$ mRNA, and protein in the hippocampus. The morphology of hippocampal pyramidal cells in the Sham group was observed to be normal. Pyramidal cells in the CPB, MLA and CPT groups were loosely arranged, and the baselines had disappeared, with clear nucleus pyknosis and neuronal apoptosis. Furthermore, the cells in the PHA group were slightly damaged. IL-1 $\beta$, IL-6, TNF- $\alpha, S-100 \beta$ and NSE expression levels in the CPB, MLA, and CPT groups were significantly higher compared with that in the Sham group $(\mathrm{P}<0.05)$. Compared with CPB group, the expression of inflammatory cytokines in the PHA group was
\end{abstract}

Correspondence to: Dr Keyan Chen, Department of Laboratory Animal Science, China Medical University, 77 Puhe Road, Shenyang North New Area, Shenyang, Liaoning 110122, P.R. China E-mail:kychen@cmu.edu.cn

Key words: $\alpha 7$ nicotinic acetylcholine receptor, cardiopulmonary bypass, neuronal cell, inflammation, TLR4 signaling pathway significantly lower $(\mathrm{P}<0.05)$. The expression of TLR4, Myd88 and NF- $\kappa \mathrm{B}$ mRNA, and protein in the hippocampus of CPB, MLA and CPT groups were significantly higher compared with that in the Sham group, and the PHA group expression was significantly lower compared with the $\mathrm{CPB}$ group $(\mathrm{P}<0.05)$. $\alpha 7 \mathrm{nAChRs}$ agonist can inhibit the apoptosis of rat brain neurons induced by $\mathrm{CPB}$, and may protect against brain injury through the TLR4/Myd88/NF- $\kappa B$ signaling pathway.

\section{Introduction}

Since cardiopulmonary bypass (CPB) technology is used in open heart surgery, the morality caused by postoperative myocardial infarction, heart failure, fatal arrhythmia and other cardiac causes has been significantly reduced (1). However, recent studies have found that patients often appear cognitive dysfunction, represented by neuropsychiatric disorders and mental disorders. The mortality rate due to neurological disorders and neuropsychiatric disorders following CPB is increasing from 7.2 to $19.6 \%(2,3)$. Temperature changes, hypotension, and other operations on the heart during CPB can cause low perfusion and hypoxia of brain tissue, ultimately leading to the occurrence of oxygen debt. Brain oxygen exposure triggers the post-trauma inflammatory response, and is a decisive factor in the cascade of inflammatory responses mediated by autoinflammatory mediators. On the other hand, full contact between blood and non-biological materials during $\mathrm{CPB}$, focal cerebral ischemia and reperfusion injury due to cerebral embolism, and endotoxemia can all induce systemic inflammatory response syndrome (SIRS) (4-6). Therefore, inflammatory response plays an important role in CPB-induced brain injury.

Excessive activation-caused inflammatory response is a crucial reasonfor the occurrence of brainnerve functional damage after CPB. Cholinergic anti-inflammatory pathway (CAP) is an endogenous neurofeedback mechanism that regulates inflammatory response of the body. $\alpha 7$ nicotinic acetylcholine receptor ( $\alpha 7 n A c h R)$ is necessary for mediating CAP, agonist CAP pathway regulates the over-activated inflammatory response by inhibiting the activation of downstream inflammatory signaling pathways (7). Toll like receptor 4 (TLR4)/myeloid differentiation primary response $88(\mathrm{Myd} 88)$ /nuclear factor $(\mathrm{NF})-\mathrm{\kappa B}$ pathway 
plays a vital role in inflammatory signaling, activation and regulation. Studies have shown that activation of $\alpha 7 \mathrm{nAchR}$ can inhibit the binding between microglia and lipopolysaccharide, significantly reduce TNF- $\alpha$ release, and exert anti-inflammatory effect in neonatal brain injury $(8,9)$. Activation of $\alpha 7 \mathrm{nAchR}$ can antagonize the toxicity of $\beta$-amyloid and serves as a treatment approach of Alzheimer's disease. Therefore, activation of $\alpha 7 \mathrm{nAChRs}$ can inhibit the inflammation via CAP and inhibit brain tissue injury.

Previous clinical and basic researches have demonstrated that CPB can cause systemic inflammatory response syndrome and brain tissue injury, induce postoperative cognitive dysfunction. CAP plays an important role in these studies. Whether $\alpha 7 n$ AChRs can inhibit the CPB-induced neuronal damage and the regulation of TLR4/Myd88/NF- $\kappa$ B pathway remains unclear. In the present study, we established CPB model in non-blood pre-filling rats and treated the models with $\alpha 7 \mathrm{nAChR}$ agonist PHA568487 and specific $\alpha 7 n$ AChR blocker MLA, aiming to investigate the protective effects and underlying mechanism of $\alpha 7 \mathrm{nAChR}$ agonist, provide evidence for formulating treatment approach of brain injury and reducing cardiovascular complications of CPB cardiovascular surgery.

\section{Materials and methods}

Animals and ethics approval.SD rats, weighing 350-400 g, were provided by Experimental Animal Center of China Medical University (production license No. SCXK (Liao)-2013-0001, application license No. SYXK (Liao)-2013-0007). The present study was approved by the China Medical University Laboratory Animal Welfare and Ethics Committee (IACUC). Experimental animals were feed in the barrier system and managed by the experimental animal professionals.

Establishment of CPB rat model. CPB was performed as previously reported with minor modifications (10). Briefly, rats were anesthetized with isoflurane; a $24 \mathrm{G}$ trocar was inserted into the right femoral vein, a $22 \mathrm{G}$ trocar was inserted into the left femoral artery, another $22 \mathrm{G}$ trocar puncture catheter was used as a perfusion artery for extracorporeal circulation. Self-made multi-hole $18 \mathrm{G}$ puncture needle arrived the right atrium through puncture catheter via the right internal jugular vein, serving as the extracorporeal venous outflow end. For the establishment of CPB model, we applied the following equipment connected with PVC tube (internal diameter $1.6 \mathrm{~mm}$ ), including venous drainage tube, blood reservoir, arterial infusion tube, filter and connecting pipe. A total of $15 \mathrm{ml}$ of circulating prefilled solution was consisted of $6 \mathrm{ml}$ hydroxyethyl starch, $6 \mathrm{ml}$ lactate Ringer's solution, $1 \mathrm{ml}$ heparin $\left(250 \mathrm{IU} \mathrm{kg}^{-1}\right), 5 \%$ sodium bicarbonate, and $1 \mathrm{ml}$ of $20 \%$ mannitol (Fig. 1-A). When CPB began, mechanical ventilation was terminated, CPB flow rate was more than $80 \mathrm{ml} / \mathrm{kg} / \mathrm{min}$, circulation volume was timely added to ensure the flow rate, flow time was $60 \mathrm{~min}$. During CPB, the oxygen-air mixture (at a ratio of 1:4) flew through the membrane lung at a rate of $800 \mathrm{ml} / \mathrm{min}$; mechanical ventilation was restarted before the flow was reduced, circulation volume was gradually decreased by adjusting the diameter of venous outflow end; the right internal jugular vein and caudal artery were ligated, followed by the removal of the catheter and suture of incision; after rats resumed spontaneous breathing, tracheal intubation was also removed and rats were fed in laboratory for observation.

Groups and treatments. Rats were randomly divided into five groups: The sham operation group (Sham group; $n=10$ ), the CPB group (CPB group; $n=10)$, the CPB $+\alpha-7 n$ AchR agonist (PHA568487) group (PHA group; $n=10$ ), the $\mathrm{CPB}+\alpha-7 \mathrm{nAchR}$ antagonist (methyllycaconitine, MLA) group (MLA group; $n=10$ ), the CPB + PHA568487 + TLR4 shRNA (CPT group; $n=10)$. In the Sham group, the intubation and mechanical ventilation were performed in the right femoral artery only and the right internal jugular vein was catheterized without bypass; in the CPB group, the CPB model was established as described above;mice in the sham and CPB groups were injected with a vehicle (Control shRNA Lentiviral Particles-A, sc-108080, Santa, USA); in the PHA group, intraperitoneal injection of $0.8 \mathrm{mg} / \mathrm{kg}$ PHA568487 (Tocris Bioscience, Ellisville, MO, USA) was performed for $30 \mathrm{~min}$ prior to the CPB establishment; in the MLA group, intraperitoneal injection of $6 \mathrm{mg} / \mathrm{kg}$ MLA (Sigma, St Louis, MO, USA) was performed for $30 \mathrm{~min}$ prior to the CPB establishment; in the CPT group, rats were also pretreated with PHA568487 $(0.8 \mathrm{mg} / \mathrm{kg})$, followed by the intraperitoneal injection of $3 \mathrm{mg} / \mathrm{kg}$ TLR4 shRNA (sc-40260-V, Santa Cruz Biotechnology, Inc., Dallas, TX, USA), and finally performed with CPB (Fig. 1-B).

Specimen collection and processing. Arterial and venous blood samples were respectively collected at CPB for $6 \mathrm{~h}$ after rats were sacrificed by administration of an overdose of anesthesia of sodium pentobarbital. After that, the hippocampus was isolated from the rat, the one side was fixed in $4 \%$ paraformaldehyde (PFA), and the other side was stored at $-80^{\circ} \mathrm{C}$ for western blot and PCR analysis. The sera were separated by centrifugation at $1,000 \mathrm{x}$ g for $10 \mathrm{~min}$, stored at $-80^{\circ} \mathrm{C}$.

HE staining of histopathological changes. Hippocampal tissues were taken at $6 \mathrm{~h}$ of CPB and fixed with neutral formalin. $48 \mathrm{~h}$ later, brain tissue was dehydrated with 70, 80, 90, 95, 100\% ethanol, xylene transparent, embedded, sliced and detected with HE staining.

Tunel staining of hippocampal neurons. The apoptosis of hippocampal neurons was detected according to the instructions of TUNEL Apoptosis Assay Kit (NO. 11684817, Roche, Mannheim, Germany). Hippocampal tissue was dehydrated, embedded, sliced and incubated with $0.9 \% \mathrm{NaCl}$ for $5 \mathrm{~min}$, then rinsed twice with PBS, mixed with biotinylated nucleotides and terminal deoxynucleotidyl transferase, covered with plastic coverslips and incubated at $37^{\circ} \mathrm{C}$ for $60 \mathrm{~min}$. After another PBS wash, brain tissue was blocked with $0.3 \%$ hydrogen peroxide, and incubated with HRP-labeled streptavidin at room temperature for $30 \mathrm{~min}$, followed by wash, DAB staining, mounting and observed under a microscope.

ELISA detection of serum levels of IL-1 $\beta, I L-6, T N F-\alpha, S-100 \beta$ and NSE. Inflammatory factors such as IL-1 $\beta$ (SEA563Ra, CCC, Compressor Controls Corporation, Des Moines, IA, USA), IL-6 (SEA079Ra, CCC, USA), TNF- $\alpha$ (SEA133Ra, CCC, USA), S-100 $\beta$ (SEA567Ra, CCC, USA) and NSE (SEA537Ra, CCC, USA) in the plasma of rats were measured by ELISA 


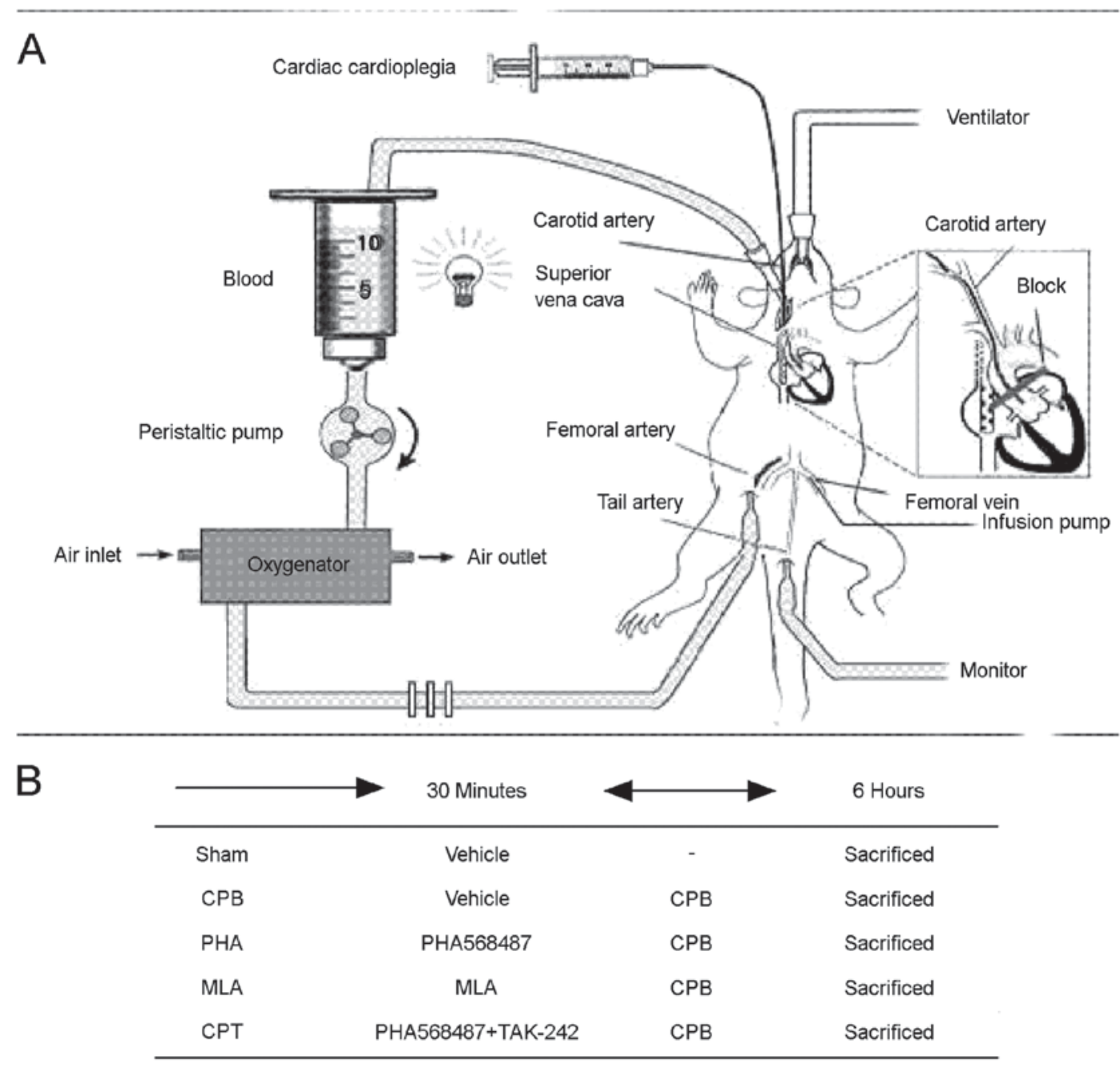

Figure 1. Schematic diagram of experimental design. (A) CPB rat model. (B) Experimental protocol in CPB rat model. CPB, cardiopulmonary bypass.

kit. After the reagents were equilibrating to room temperature $\left(20-25^{\circ} \mathrm{C}\right)$, reaction plate was taken out and added with $100 \mu 1$ standard sample and $100 \mathrm{ul}$ diluted sample, gently shaking for $30 \mathrm{sec}$ and incubating at $20-25^{\circ} \mathrm{C}$ for $20 \mathrm{~min}$; each hole within the reaction plate was added with $100 \mu 1$ serum sample and incubated at $37^{\circ} \mathrm{C}$ for $2 \mathrm{~h}$; then, $100 \mu \mathrm{l} \mathrm{HRP-labeled} \mathrm{antibody}$ was added to each hole and incubated at $37^{\circ} \mathrm{C}$ for $30 \mathrm{~min}$; after another wash, color liquids $\mathrm{A}$ and $\mathrm{B}$, each $50 \mu \mathrm{l}$, was added for developing and the reaction was terminated with $50 \mu \mathrm{l}$ solution. The optical density (OD) at $450 \mathrm{~nm}$ was measured with microplate reader; standard curve was plotted taking the OD value as the ordinate and standard sample concentration as the abscissa, the curve equation and $r$ value were calculated, thus the sample concentration value was measured.

Western blot analysis. The hippocampal tissue was grid and centrifuged in a pre-chilled tissue lysate at 12,000 rpm for $30 \mathrm{~min}$. The supernatant of total protein was extracted for SDS-PAGE and the protein was semi-dried for membrane transfer. The cells were blocked $2 \mathrm{~h}$ and incubated overnight at $4^{\circ} \mathrm{C}$ with TLR4 (ab22048, Abcam, Cambridge, MA, USA), Myd88 (ab2068, Abcam, USA), NF-кB antibody (ab32360, Abcam, USA), followed three washes and incubation with secondary antibody for $1 \mathrm{~h}$. After four washes using TBST,
Table I. Primer sequences.

\begin{tabular}{ll}
\hline ITEAM & \multicolumn{1}{c}{ PRIMER SEQUENCES } \\
\hline Myd88 & P1:agatccgcga gtttgagacg cg \\
& P2:ctttctacca accttctgta cg \\
TLR9 & P1:ctctcctggt acaggctgca gt \\
& P2:cctggcaagt tccttcaaga gc \\
NF-אB & P1:cggcctcatc cacatgaact tgt \\
& P2:ctaaggcact gatggtgacc ct \\
GAPDH & P1:aactttggcattgtggaagg \\
& P2:cacattgggggtaggaacac \\
\hline
\end{tabular}

cells were developed with ECL Western Blotting Substrate kit (32109, Pierce ${ }^{\mathrm{TM}}$, Thermo Fisher Scientific, Waltham, MA, USA) and gray value was measured by using Quantity One software.

Realtime-PCR detection. Primers were designed according to the sequences of TLR4, Myd88, NF- $\mathrm{BB}$ and GAPDH reported in Genbank, and were synthesized in Shanghai Biomedical Biotechnology Co., Ltd., (Shanghai, China) (Table I). Rat 


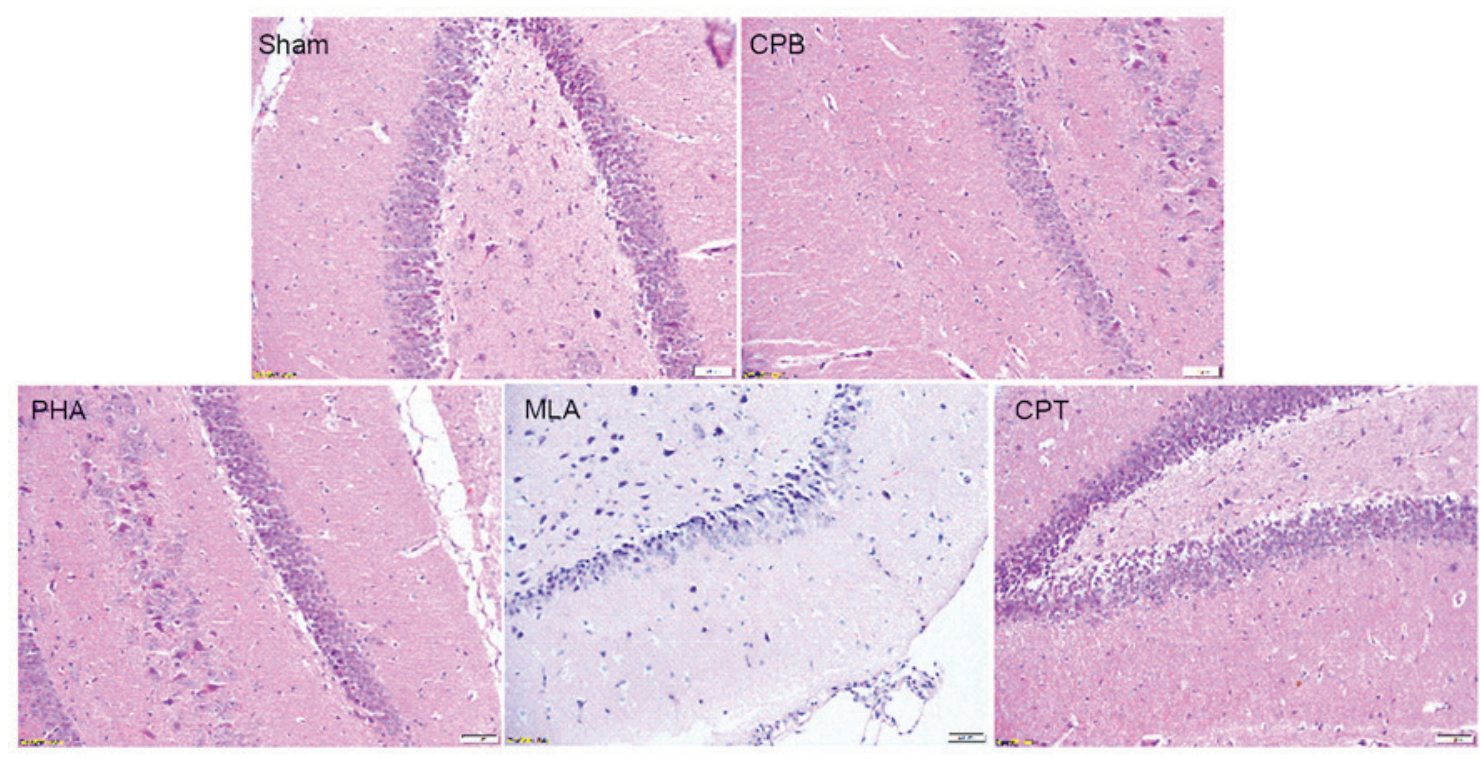

Figure 2. $\alpha-7 \mathrm{nAchR}$ agonist alleviates pathological injury in hippocampus. Sham group: There was no evidence of morphological damage; CPB group: Obvious cellular degeneration and abnormal cell arrangements; PHA group: Only a slight morphological; MLA and CPT group: The typical vacuolated degenerations in hippocampal neurons.

hippocampus total RNA was isolated with TRIzol reagent (15596018, Invitrogen, Carlsbad, CA, USA).and reversely transcribed into cDNA (4387406, Invitrogen, USA). Real-time PCR kit (RR820A, Takara Bio, Dalian, China) was used for the detection.

Statistical analysis. Data were analyzed using SPSS 19.0 statistical software, measurement data were expressed as mean \pm standard deviation. Comparisons between groups were made using the Student's t-test (two-tailed) or ANOVA with Tukey's post-test analysis. $\mathrm{P}<0.05$ was considered to indicate a statistically significant difference.

\section{Results}

Hippocampal pathological detection results. HE staining showed that hippocampal neurons in Sham group were arranged in a regular and close manner, with clear boundary and complete cell band, and no abnormal cell structure was found. The hippocampus in CPB, MLA and CPT group were severely damaged, the damage in the PHA group was lighter than that of the CPB group, cells were tightly arranged and cell band was not complete (Fig. 2).

Hippocampal neuronal apoptosis. Compared with Sham group, the number of TUNEL-positive cells in CPB, MLA and CPT group were significantly increased $(\mathrm{P}<0.05)$; compared with CPB group, the number of TUNEL-positive cells in the hippocampus of PHA group was significantly decreased $(\mathrm{P}<0.05)$ (Fig. 3).

Changes of IL-1 $\beta, I L-6$ and TNF- $\alpha$ in serum. Compared with Sham group, the levels of IL-1 $\beta$, IL- 6 and TNF- $\alpha$ in CPB, MLA and CPT group were significantly increased $(\mathrm{P}<0.05)$; compared with CPB group, IL-1 $\beta$, IL-6 and TNF- $\alpha$ levels in PHA group were significantly decreased $(\mathrm{P}<0.05)$ (Fig. 4).
Changes of $S-100 \beta$ and NSE levels. The expression of S-100 $\beta$ and NSE in CPB, MLA and CPT group were significantly higher than those in Sham group $(\mathrm{P}<0.05)$. Compared with CPB group, the expressions of S-100 $\beta$ and NSE in PHA group were significantly decreased $(\mathrm{P}<0.05)$ (Fig. 5).

Detection of TLR4, Myd88, NF- $\kappa B$ mRNA and protein. The expressions of TLR4, Myd88, NF- $\kappa \mathrm{B}$ mRNA and protein in $\mathrm{CPB}, \mathrm{MLA}$ and CPT group were significantly higher than those in Sham group $(\mathrm{P}<0.05)$. Compared with CPB group, TLR4, Myd88, NF- $\kappa$ B expression in brain tissue of PHA group were significantly decreased $(\mathrm{P}<0.05)$ (Fig. 6).

\section{Discussion}

In the present study, we observed the changes of neuronal morphology, the expression of inflammatory factor and TLR4, Myd88, NF- $\kappa$ B pathway in rat hippocampus by HE and TUNEL staining, ELISA assay and western blot analysis. Results showed that PHA568487 could decrease the morphological changes of hippocampus, downregulate the expression of inflammatory factors and the apoptosis. In addition, PHA568487 contribute to reduce CPB-induced TLR4, Myd88, NF- $\kappa$ B pathway protein expression. This evidence suggests that PHA568487 can attenuate CPB-induced brain injury in rats, the underlying mechanism may be mediated through the regulation of TLR4, Myd88, NF- $\mathrm{B}$ pathway. The incidence of CPB-induced brain injury is increasing year by year, becoming an urgent problem, the present study provides experimental and theoretical evidence for the modification of perioperative brain protection of heart surgery.

At present, $\mathrm{CPB}$ is the main means of clinical open heart surgery, as CPB devices are continuously developing, anesthesia techniques and surgical skills gradually increase, heart surgery complications and mortality are significantly reduced (11). However, increasing number of previous studies 


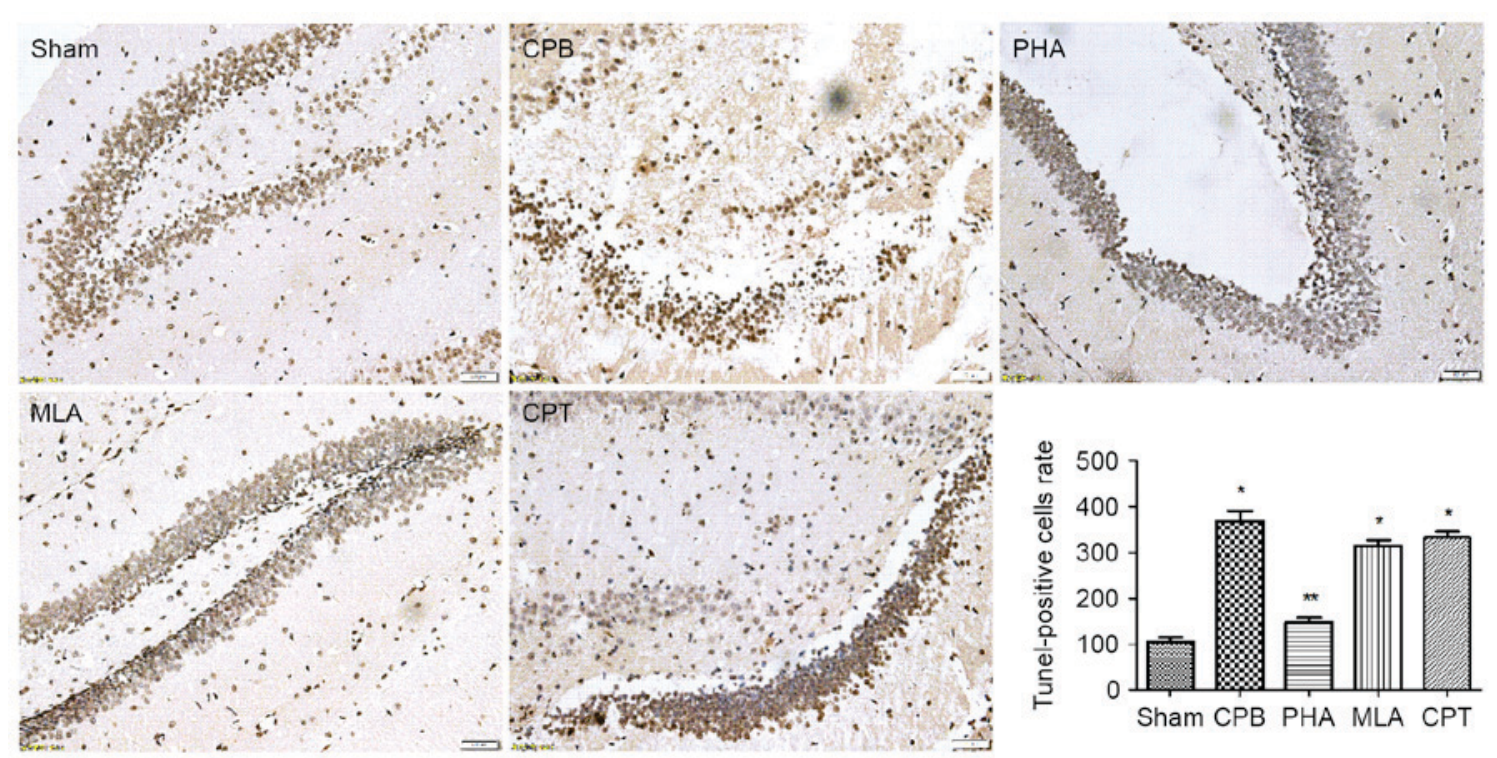

Figure 3. $\alpha-7 n$ AchR agonist inhibits neuronal apoptosis in hippocampus. Sham group: There was no evidence of neuronal apoptosis; CPB group: The neurons exhibited the typical apoptosis; PHA group: Only a slight neuronal apoptosis; MLA and CPT group: The neuronal apoptosis in hippocampal neurons. Compared with Sham group, ${ }^{*} \mathrm{P}<0.05$, Compared with $\mathrm{CPB}$ group, ${ }^{* *} \mathrm{P}<0.05$.
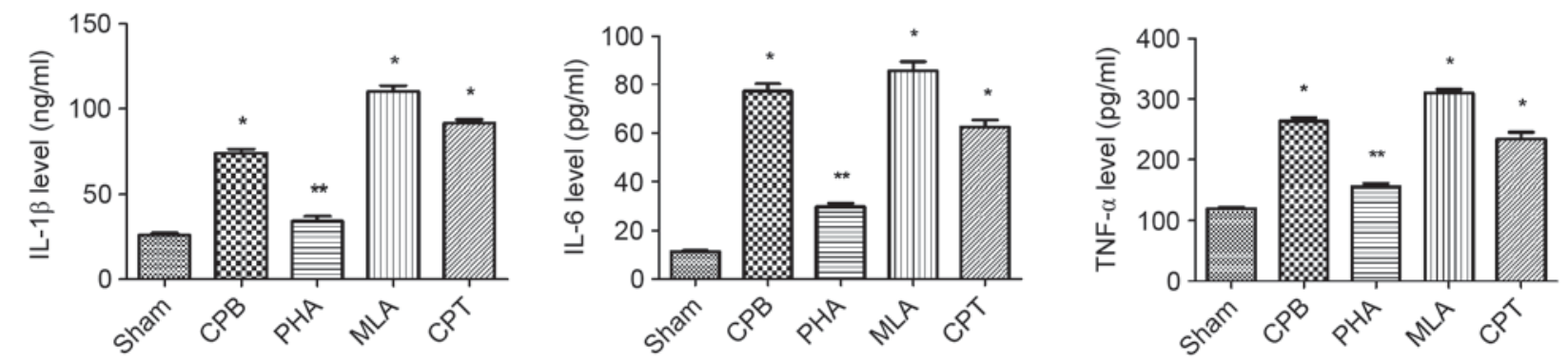

Figure 4. $\alpha-7$ nAchR agonist reduces the serum levels of IL-1 $\beta$, TNF $\alpha$ and IL6 in CPB-injured rats. Compared with S group, "P<0.05; Compared with CPB group ${ }^{* *} \mathrm{P}<0.05$.
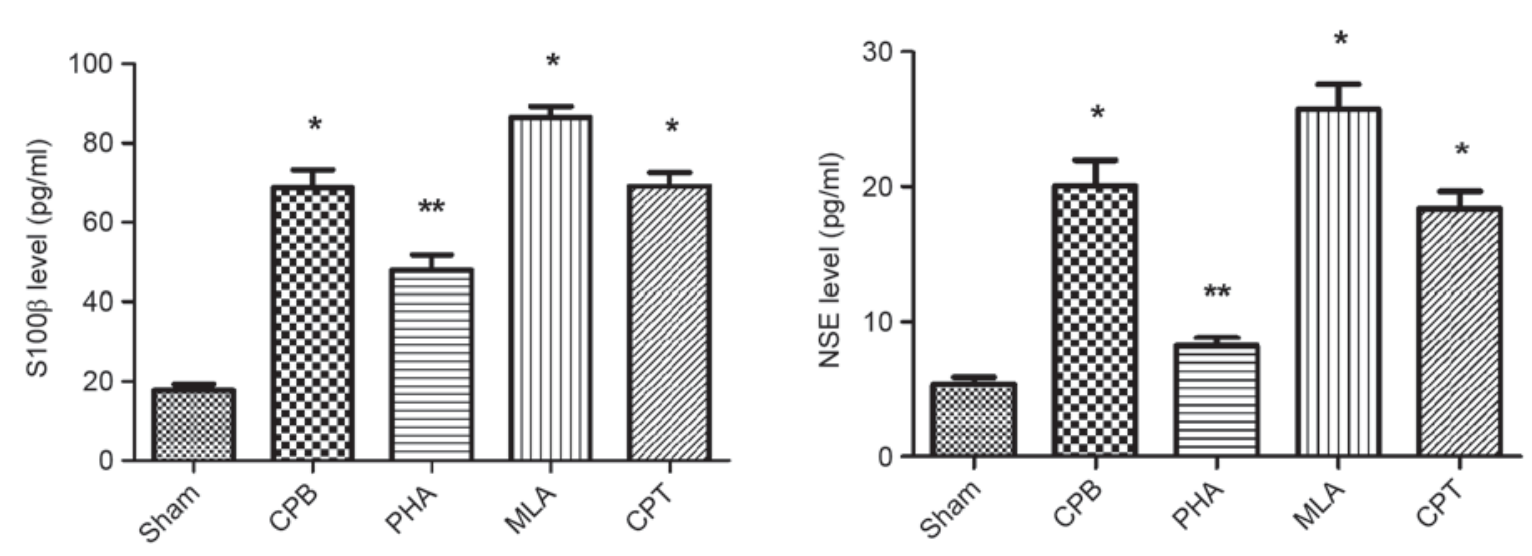

Figure 5. $\alpha-7 \mathrm{nAchR}$ agonist reduces the levels of S-100 $\beta$ and NSE in CPB-injured rats. Changes of S-100 $\beta$ and NSE in brain tissue were detected by ELISA. Compared with Sham group, ${ }^{*} \mathrm{P}<0.05$; Compared with $\mathrm{CPB}$ group ${ }^{* *} \mathrm{P}<0.05$.

have reported the CPB-induced brain injury and related inflammatory response, leaving its pathogenesis unclear $(12,13)$. A good CPB model is essential for the study of therapeutic and prophylactic measures. In the present study, CPB model was established by injecting $6 \%$ hydroxyethyl starch into SD rats through right venous drainage and right femoral arterial fusion. HE staining and ELISA assay showed that, CPB caused brain tissue injury characterized by neuronal apoptosis, increased brain injury markers significantly, especially serum inflammatory factors were increased significantly at postoperative 
A

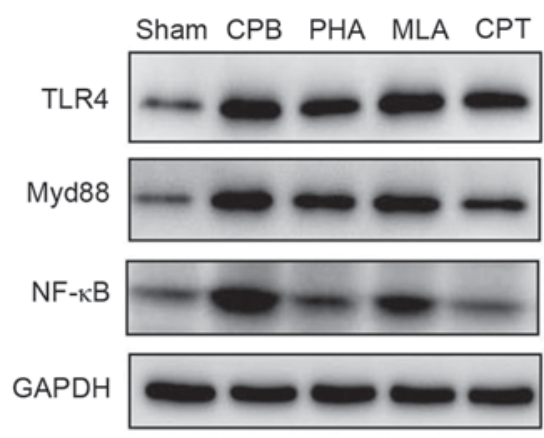

B
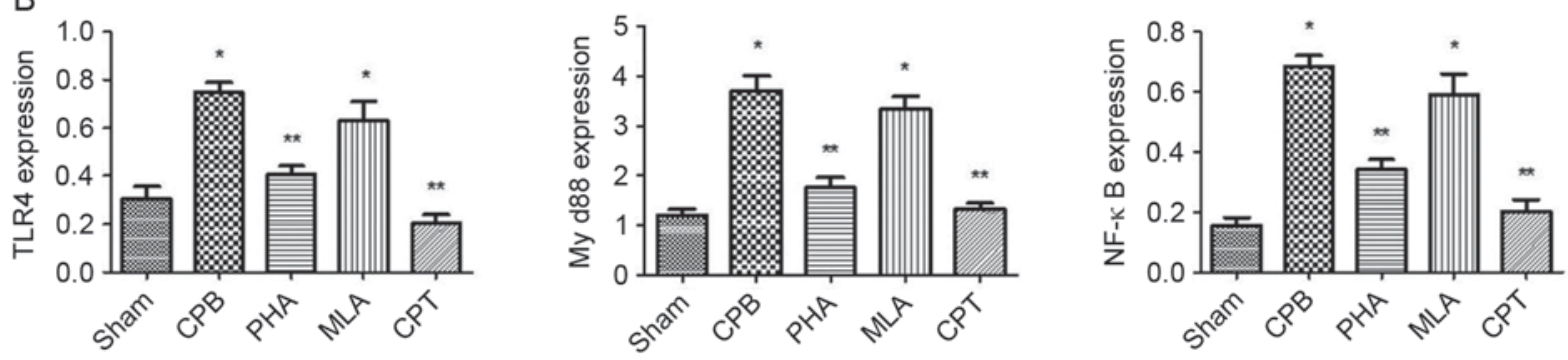

C
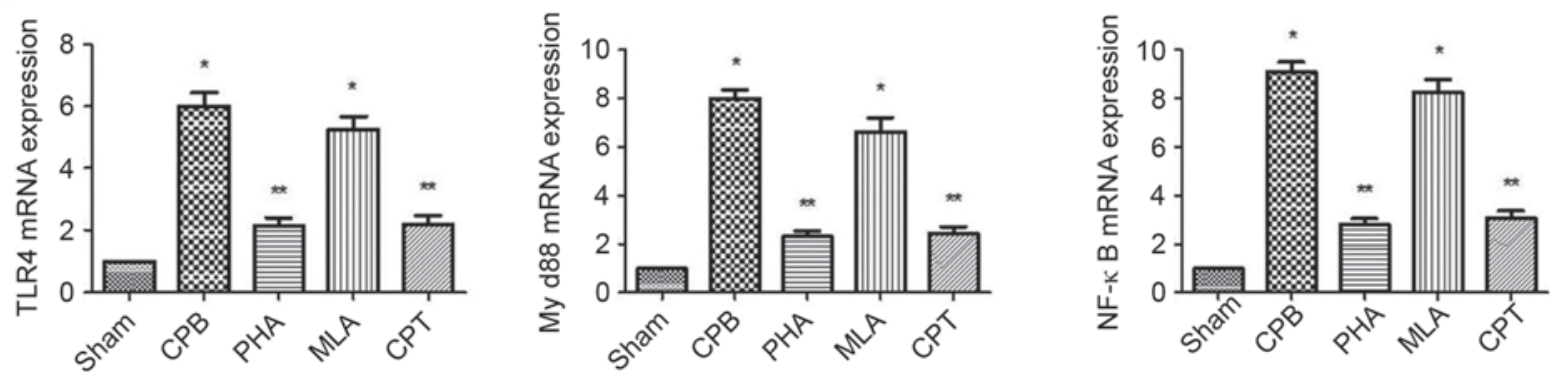

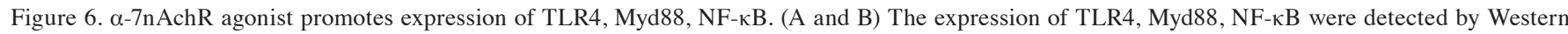
blot; (C) The expression of TLR4, Myd88, NF-кB were detected by Realtime-PCR. Compared with Sham group, ${ }^{*} \mathrm{P}<0.05$, Compared with CPB group ** $\mathrm{P}<0.05$.

$2 \mathrm{~h}$. This finding suggested that $\mathrm{CPB}$ can induce brain neuron injury and systemic inflammatory response. On the other hand, the model is established successfully, which can reflect clinical features and can be used as experimental tool to study systemic inflammatory response, organ protection mechanism and related protection measures.

CAP is an endogenous neurofeedback regulation, studies have shown that cholinergic agonists acting on $\alpha 7 \mathrm{nAChR}$-knockout macrophages can not produce the desired anti-inflammatory effect, suggesting that $\alpha 7 n A c h R$ is the necessary receptor for CAP (14). Under the stimuli of infection, injury or embolism, vagus nerve is activated, a large number of Ach release into peripheral tissue and bind with macrophages, microglia and other antibody on the surface of immune cells $(14,15)$. Activation of $\alpha 7 \mathrm{n}$ AchR, cholinergic anti-inflammatory signal can inhibit the release of IL-1 $\beta$, IL-6, TNF- $\alpha$ and other inflammatory cytokines and endotoxin through the various signal transduction pathways in the cells, increase the formation of anti-inflammatory factors, thus producing a rapid and efficient regulation of inflammatory response $(16,17)$. Previous studies have found that, $\alpha 7 \mathrm{nAChR}$ agonists can not only exert clear anti-inflammatory effect for cerebral embolism-caused neuropathic inflammatory response, fracture-caused inflammatory brain injury and neonatal encephalitis, but also improve postoperative cognitive dysfunction and Alzheimer's disease $(18,19)$. Activation of $\alpha 7 \mathrm{nAChR}$ induces the upregulation of its function, antagonizes the toxicity of $\beta$-amyloid (A $\beta$ ), modulates downstream signal transduction and thus improves cognitive memory impairment (20). A7nAChR agonist PHA568487 can improve cognitive impairment such as schizophrenic symptoms in the MK801 mouse model of spatial memory impairment (21). In the ischemic stroke model, the protection effect of $\alpha 7 \mathrm{nAChR}$ agonist PHA568487 is achieved by reducing the macrophage release of inflammatory factors and the body's oxidative stress. Furthermore, $\alpha 7 \mathrm{nAchR}$ agonist could protect primary brain cortical neurons from oxygen-glucose deprivation injury model after culture for 7 days in vitro (22). The protection effect was associated with anti-oxidative stress. In the present study, we found that compared with the CPB group, brain injury was attenuated, neuronal apoptosis rate was decreased, the levels of IL- $1 \beta$, IL- 6 and TNF- $\alpha$ was lower, the concentration of S100 $\beta$ and NSE in the brain tissue was also lower in the $\alpha 7 \mathrm{nAChR}$ agonist group, suggesting that $\alpha 7 \mathrm{nAChR}$ agonists protect against CPB-induced brain injury.

PreviousstudieshavedemonstratedthatTLR4/Myd88/NF-кB signaling pathway is involved in the damage of neuronal cells during cerebral ischemia $(23,24)$. TLRs is expressed on various kinds of immune cells, and TLR4 is mainly expressed on monocytes and macrophages and dendritic cells. TLR4 through 
the selective recognition of PAMPs such as lipopolysaccharide, flagellin and microbial nucleic acid and endogenous molecules damage associated molecular patterns such as tissue injury necrosis by the release of hyaluronic acid, high mobility group protein 1, heat shock protein, triggered Myd88 dependent and independent pathways, the final activation of $\mathrm{NF}-\kappa \mathrm{B}$, leading to TNF- $\alpha$, IL-6, IL-1 $\beta$ and other inflammatory cytokines and chemokine release induced inflammation (25). Kong et al (26) found in macrophage research, TLR4/Myd88/NF- $\kappa \mathrm{B}$ and the expression of many inflammatory factors regulation and control, curcumin can inhibit the inflammatory reaction through the TLR4/Myd88/NF-кB. Zhu et al (27) in the acute brain injury research shows that Curcumin can inhibit the inflammatory response through the TLR4/Myd88/NF- $\kappa \mathrm{B}$ signaling pathway.

In summary, the expression of TLR4, Myd88, NF- $\kappa \mathrm{B}$ protein in the hippocampus of CPB rats were significantly increased compared with the control group, and the expression of TLR4, Myd88, NF- $\mathrm{B}$ was significant decreased after the intervention of $\alpha 7 \mathrm{nAChR}$ agonist. The results suggest that $\alpha 7 \mathrm{nAChR}$ agonists protect brain neurons against CPB-induced injury in rats by activating TLR4, Myd88, NF-кB pathway.

\section{Acknowledgements}

The present study was supported by the Natural Science Foundation of China (grant no. 81471121 and no. 3120175). New teacher foundation of China Medical University (XZR20160036).

\section{References}

1. Boshes B, Priest WS, Yacorzynski GK and Zaks MS: The neurologic, psychiatric and psychologic aspects of cardiac surgery. Med Clin North Am 41: 155-169, 1957.

2. Hannan E L, Racz M J, Walford G, Jones RH, Ryan TJ, Bennett E, Culliford AT, Isom OW, Gold JP and Rose EA: Long-term outcomes of coronary-artery bypass grafting versus stent implantation. N Engl J Med 352: 2174-2183, 2005.

3. Knipp SC, Matatko N, Wilhelm H, Schlamann M, Thielmann M, Lösch C, Diener HC and Jakob H: Cognitive outcomes three years after coronary artery bypass surgery: Relation to diffusion-weighted magnetic resonance imaging. Ann Thorac Surg 85: 872-879, 2008

4. Plicner D, Stoliński J, Wasowicz M, Gawęda B, Hymczak H, Kapelak B, Drwiła R and Undas A: Preoperative values of inflammatory markers predict clinical outcomes in patients after CABG, regardless of the use of cardiopulmonary bypass. Indian Heart J 68 (Suppl 3): S10-S15, 2016.

5. Boehne M, Sasse M, Karch A, Dziuba F, Horke A, Kaussen T1, Mikolajczyk R, Beerbaum P and Jack T: Systemic inflammatory response syndrome after pediatric congenital heart surgery: Incidence, risk factors, and clinical outcome. J Card Surg 32: 116-125, 2017

6. Liu Y, Yang J, Bao J, Li X, Ye A, Zhang G and Liu H: Activation of the cholinergic anti-inflammatory pathway by nicotine ameliorates lipopolysaccharide-induced preeclampsia-like symptoms in pregnant rats. Placenta 49: 23-32, 2017.

7. Xiong J, Yuan YJ, Xue FS, Wang Q, Cheng Y, Li RP, Liao X and Liu JH: Postconditioning with $\alpha 7 \mathrm{nAChR}$ agonist attenuates systemic inflammatory response to myocardial ischemia-reperfusion injury in rats. Inflammation 35: 1357-1364, 2012.

8. Frasch MG, Szynkaruk M, Prout AP, Nygard K, Cao M, Veldhuizen R, Hammond R and Richardson BS: Decreased neuroinflammation correlates to higher vagus nerve activity fluctuations in near-term ovine fetuses: A case for the afferent cholinergic anti-inflammatory pathway? J Neuroinflammation 13: 103, 2016

9. Ghijselings I, Himpe D and Rex S: Safety of gelatin solutions for the priming of cardiopulmonary bypass in cardiac surgery: A systematic review and meta-analysis. Perfusion 32: 350-362, 2017.
10. Cao HJ, Sun YJ, Zhang TZ, Zhou J and Diao YG: Penehyclidine hydrochloride attenuates the cerebral injury in a rat model of cardiopulmonary bypass. Can J Physiol Pharmacol 91: 521-527, 2013.

11. Lomivorotov VV, Shmyrev VA, Ponomarev DN, Efremov SM, Shilova AN and Postnov VG: Influence of remote ischemic preconditioning on brain injury markers dynamics during cardiopulmonary bypass. Anesteziol Reanimatol 60: 33-38, 2015 (In Russian).

12. von Rhein M, Buchmann A, Hagmann C, Huber R, Klaver P, Knirsch W and Latal B: Brain volumes predict neurodevelopment in adolescents after surgery for congenital heart disease. Brain 137: 268-276, 2014

13. Ni M, Fu H, Huang F, Zhao T, Chen JK, Li DJ and Shen FM: Vagus nerve attenuates hepatocyte apoptosis upon ischemia-reperfusion via $\alpha 7$ nicotinic acetylcholine receptor on kupffer cells in mice. Anesthesiology 125: 1005-1016, 2016.

14. Wang C, Chen H, Zhu W, Xu Y, Liu M, Zhu L, Yang F, Zhang L, Liu X, Zhong Z, et al: Nicotine accelerates atherosclerosis in apolipoprotein E-deficient mice by activating $\alpha 7$ nicotinic acetylcholine receptor on mast cells. Arterioscler Thromb Vasc Biol 37: 53-65, 2017.

15. Xu ZQ, Shao BZ, Ke P, Liu JG, Liu GK, Chen XW, Su DF and Liu C: Combined administration of anisodamine and neostigmine rescued acute lethal crush syndrome through $\alpha 7 n$ AChR-dependent JAK2-STAT3 signaling. Sci Rep 6: 37709, 2016.

16. Chen XM, Li FQ, Yan S, Wu XC and Tang CL: Nicotine alleviates the liver inflammation of non-alcoholic steatohepatitis induced by high-fat and high-fructose in mice. Beijing Da Xue Xue Bao 48: 777-782, 2016 (In Chinese).

17. Carnevale D, Perrotta M, Pallante F, Fardella V, Iacobucci R, Fardella S, Carnevale L, Carnevale R, De Lucia M, Cifelli G and Lembo G: A cholinergic-sympathetic pathway primes immunity in hypertension and mediates brain-to-spleen communication. Nat Commun 7: 13035, 2016.

18. Frasch MG, Szynkaruk M, Prout AP, Nygard K, Cao M, Veldhuizen R, Hammond R and Richardson BS: Decreased neuroinflammation correlates to higher vagus nerve activity fluctuations in near-term ovine fetuses: A case for the afferent cholinergic anti-inflammatory pathway? J Neuroinflammation 13: 103, 2016.

19. Arèvalo-Serrano J, Sanz-Anquela JM and Gonzalo-Ruiz A: Beta-amyloid peptide-induced modifications in alpha7 nicotinic acetylcholine receptor immunoreactivity in the hippocampus of the rat: Relationship with GABAergic and calcium-binding proteins perikarya. Brain Res Bull 75: 533-544, 2008.

20. Ge J, Tian J, Yang H, Hou L, Wang Z, He Z and Wang X: ALPHA7 nicotine acetylcholine receptor agonist PNU-282987 attenuates acute lung injury in a cardiopulmonary bypass model in rats. Shock 47: 474-479, 2017.

21. Wang H, Yu M, Ochani M, Amella CA, Tanovic M, Susarla S, Li JH, Wang H, Yang H, Ulloa L, et al: Nicotinic acetylcholine receptor alpha7 subunit is an essential regulator of inflammation. Nature 421: 384-388, 2003.

22. Feng H, Su R, Song Y, Wang C, Lin L, Ma J and Yang H: Positive correlation between enhanced expression of TLR4/MyD88/NF- $\kappa$ B with insulin resistance in placentae of gestational diabetes mellitus. PLoS One 11: e0157185, 2016.

23. Kim SH, Bang J, Son CN, Baek WK and Kim JM: Grape seed proanthocyanidin extract ameliorates murine autoimmune arthritis through regulation of TLR4/MyD88/NF- $\kappa$ Bsignaling pathway.KoreanJInternMed,Jun3, 2016 (Epub ahead of print).

24. Han LP, Li CJ, Sun B, Xie Y, Guan Y, Ma ZJ and Chen LM: Protective effects of celastrol on diabetic liver injury via TLR4/MyD88/NF- $\mathrm{kB}$ signaling pathway in type 2 diabetic rats. J Diabetes Res 2016: 2641248, 2016.

25. Li Y, Xie G, Li L, Jiang Z, Yue Z and Pan Z: The effect of TLR4/MyD88/NF- $\kappa \mathrm{B}$ signaling pathway on proliferation and apoptosis in human nasopharyngeal carcinoma $5-8 \mathrm{~F}$ cells induced by LPS. Lin Chung Er Bi Yan Hou Tou Jing Wai Ke Za Zhi 29: 1012-1015, 2015.

26. Kong F, Ye B, Cao J, Cai X, Lin L, Huang S, Huang W and Huang Z: Curcumin represses NLRP3 inflammasome activation via TLR4/MyD88/NF- $\mathrm{kB}$ and P2X7R signaling in PMA-induced macrophages. Front Pharmacol 7: 369, 2016.

27. Zhu HT, Bian C, Yuan JC, Chu WH, Xiang X, Chen F, Wang CS, Feng $\mathrm{H}$ and Lin JK: Curcumin attenuates acute inflammatory injury by inhibiting the TLR4/MyD88/NF- $\kappa \mathrm{B}$ signaling pathway in experimental traumatic brain injury. J Neuroinflammation 11: 59, 2014. 